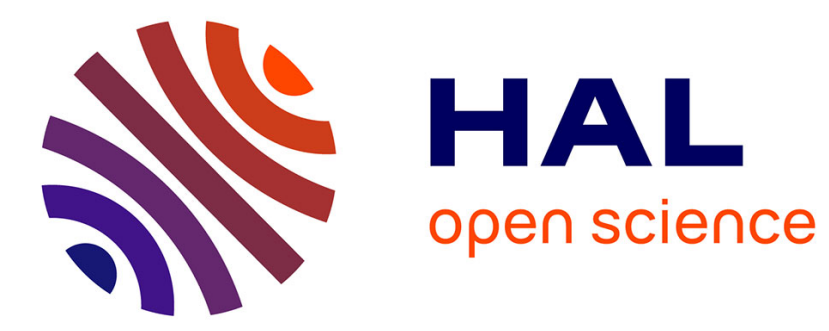

\title{
Tuning the chaotropic effect as an assembly motif through one-electron transfer in a rhenium cluster
}

Anton Ivanov, Clement Falaise, David Landy, Mohamed Haouas, Yuri V

Mironov, Michael A Shestopalov, Emmanuel Cadot

\section{To cite this version:}

Anton Ivanov, Clement Falaise, David Landy, Mohamed Haouas, Yuri V Mironov, et al.. Tuning the chaotropic effect as an assembly motif through one-electron transfer in a rhenium cluster. Chemical Communications, 2019, 55 (67), pp.9951-9954. 10.1039/c9cc05136h . hal-02335733

\section{HAL Id: hal-02335733 \\ https://hal.science/hal-02335733}

Submitted on 28 Oct 2019

HAL is a multi-disciplinary open access archive for the deposit and dissemination of scientific research documents, whether they are published or not. The documents may come from teaching and research institutions in France or abroad, or from public or private research centers.
L'archive ouverte pluridisciplinaire HAL, est destinée au dépôt et à la diffusion de documents scientifiques de niveau recherche, publiés ou non, émanant des établissements d'enseignement et de recherche français ou étrangers, des laboratoires publics ou privés. 
Received 00th January 20xx, Accepted 00th January 20xx

DOI: $10.1039 / x 0 x \times 00000 x$

\section{Tuning the chaotropic effect as an assembly motif through one- electron transfer in rhenium cluster}

\author{
Anton A. Ivanov, ${ }^{\mathrm{a}, \mathrm{b}, \mathrm{c}}$ Clément Falaise, ${ }^{\mathrm{a}}$ David Landy, ${ }^{\mathrm{d}}$ Mohamed Haouas, ${ }^{\mathrm{a}}{ }^{\mathrm{a}}$ Yuri V. Mironov, ${ }^{\mathrm{b}, \mathrm{e}}$
} Michael A. Shestopalov ${ }^{\mathrm{b}, \mathrm{c}, \mathrm{e}}$ and Emmanuel Cadot*a
We report how only one electron transfer from the hydrophilic reduced cluster $\left[\left\{\mathrm{Re}_{6} \mathrm{Se}_{8}\right\}(\mathrm{CN})_{6}\right]^{4-}$ induces both a dramatic increase of the host-guest affinity with $\gamma$-cyclodextrin and a drastic alteration of the supramolecular dynamics. This striking behaviour, underlined by its thermochemical fingerprint, evidences the self-assembly process is driven by chaotropic effect.

Supramolecular approach for designing smart materials are of considerable interest on account of wide range of newfound potential applications which can be imparted in diverse fields such as medicine, energy conversion, information storage, and green catalysis. Mimicking the "lock and key" systems functioning in biological machinery such as receptor-effector recognition in proteins, ${ }^{1}$ this conceptual approach targets to develop molecular devices built from complex self-assembled structures, ${ }^{2}$ as tools for electronic and biological interfacing ${ }^{3}$ or synthetic self-replicating systems. ${ }^{4}$ Cyclodextrins (CDs) are cyclic oligosaccharides built from glucopyranose units, which have already shown to behave as effective host to encapsulate different hydrophobic entities to form biomedical drugs. ${ }^{5}$ Recently, inorganic species such as dodecaborates, ${ }^{6,7}$ polyoxometalates $^{8-11}$ or metal cluster complexes ${ }^{12-14}$ were found to form inclusion complexes with one or two CDs existing both in water solution and solid-state. Solvent effects arising from these ionic species have been identified as the main contributor to the host-guest self-assembly processes in these systems. ${ }^{15}$ More precisely, their water structurebreaking ability, namely the chaotropic effect favours creation of host-guest interface through desolvation process, resulting

\footnotetext{
${ }^{a .}$ Institut Lavoisier de Versailles, CNRS, UVSQ, Université Paris-Saclay, Versailles, France.

${ }^{b .}$ Nikolaev Institute of Inorganic Chemistry SB RAS, Novosibirsk, 630090, Russia.

c. The Federal Research Center of Fundamental and Translational Medicine,

Novosibirsk, 630117 Russia.

${ }^{d .}$ Unité de Chimie Environnementale et Interactions sur le Vivant (UCEIV, EA 4492), ULCO, Dunkerque, France.

e. Novosibirsk State University, Novosibirsk, 630090, Russia.

† Footnotes relating to the title and/or authors should appear here.

Electronic Supplementary Information (ESI) available: Experimental details of syntheses methods and physical characterizations; Single crystal XRD data; NMR relaxation measurements; Electrochemistry experiments. See DOI: $10.1039 / x 0 \times x 00000 x$
}

from the water structure reconstruction, pointed as the main contributor of the supramolecular recognition. Furthermore, the extremely large magnitude of this effect featured by highly stable supramolecular adducts allowed considering such fascinating phenomenon as an effective assembly motif in supramolecular chemistry, opening new avenues for designing multifunctional soft materials. ${ }^{15}$ In context, special attention is given to octahedral rhenium cluster complexes $\left[\left\{\operatorname{Re}_{6} \mathrm{Q}_{8}\right\} \mathrm{L}_{6}\right]^{\mathrm{n}}$ due to their redox and photoluminescence properties, and high radiodensity, ${ }^{16}$ which in combination with solubility increase in aqueous CD media are promising for numerous applications ranging from photodynamic therapy ${ }^{17}$ or computed tomography ${ }^{18}$ to photocatalysis. ${ }^{19}$ Previous reports have shown the host-guest affinity depends on both inner and apical ligands of the octahedral cluster and also on the size of cyclodextrins (Fig. 1), demonstrating that several contributors operate within the host-guest recognition process. ${ }^{12-14}$
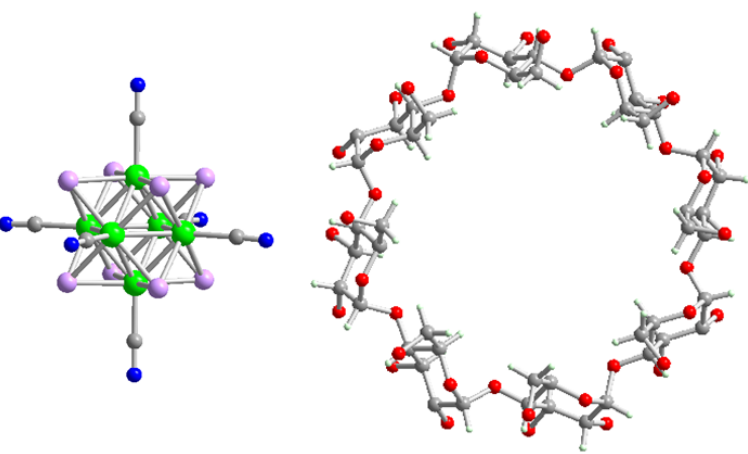

Figure 1 Structural representations of molecular components used as guest and host units. The $\left[\left\{\mathrm{Re}_{6} \mathrm{Se}_{8}\right\}(\mathrm{CN})_{6}\right]^{3-/ 4-}$ cluster contains six rhenium ions (green sphere) disposed on the octahedron corners while the selenium atoms (inner ligand) are located on the eight faces of the octahedron and the terminal cyano groups (outer ligands) complete the coordination sphere of the rhenium atoms. The $\gamma$-cyclodextrin macrocycle $\mathrm{C}_{48} \mathrm{H}_{80} \mathrm{O}_{40}$ results from the condensation of eight glucopyranose units $\left\{\mathrm{C}_{6} \mathrm{H}_{10} \mathrm{O}_{5}\right\}$ and delimits a large inner cavity of about $10 \AA ̊$ in diameter.

Herein, we report how a single-electron transfer leading to the oxidized species $\left[\left\{\mathrm{Re}_{6} \mathrm{Se}_{8}\right\}(\mathrm{CN})_{6}\right]^{3-}$ from the reduced one $\left[\left\{\mathrm{Re}_{6} \mathrm{Se}_{8}\right\}(\mathrm{CN})_{6}\right]^{4-}$ affects drastically the host-guest stability in solution. While keeping constant the cluster composition and 
even unchanged the structure of the host-guest assemblies through the electron transfer, such results are interpreted as chaotropic-driven effects of the involved redox species.

As starting point, we showed in previous report the redox properties of octahedral clusters were able to be significantly altered through the inclusion process. ${ }^{13}$ Depending on the host-guest system type, distinct electrochemical behaviours have been distinguished. While the appearance of new redox signals features the formation of frozen host-guest adducts, the gradual change of the redox potential, on the other hand, indicates labile exchange of the CD occurring concomitantly with the electron transfer. Then, analysis of electrochemical behaviours of these host-guest arrangements gives indirect highlights about change of the cluster-CD affinity in the course of the redox process. In short, the decrease of the standard potential through the formation of the supramolecular arrangement should underline the significant increase of the host-guest stability when the redox state of the guest changes from $\left[\left\{\operatorname{Re}_{6} \mathrm{Q}_{8}\right\}(\mathrm{CN})_{6}\right]^{4-}$ to $\left[\left\{\operatorname{Re}_{6} \mathrm{Q}_{8}\right\}(\mathrm{CN})_{6}\right]^{3-}$. $^{13}$ Full understanding of the solution behaviour for this class of multifunctional clusters is prerequisite prior to any rational use in specific assembly. The oxidized cluster $\left[\left\{\mathrm{Re}_{6} \mathrm{Se}_{8}\right\}(\mathrm{CN})_{6}\right]^{3-}$ (noted $\mathbf{R e}_{6} \mathbf{O x}$ ) has been quantitatively prepared from the reduced parent $\left[\left\{\mathrm{Re}_{6} \mathrm{Se}_{8}\right\}(\mathrm{CN})_{6}\right]^{4-}$ (noted $\mathbf{R e}_{6}$ red) through chemical oxidation using bromine as oxidant (see ESI for further details). Electrochemical characterization using rotating disc electrode is fully consistent with one-electron process according to the literature results (Fig. 2a). ${ }^{[20]}$ While the cyclic voltammetry of both $\left[\left\{\mathrm{Re}_{6} \mathrm{Se}_{8}\right\}(\mathrm{CN})_{6}\right]^{4-/ 3-}$ species was similar and fully consistent with a reversible one-electron transfer, complexation of the cluster by $\gamma-C D$ alters significantly the electrochemical process as observed by the redox potential decrease of about $120 \mathrm{mV}$ and by a nearly irreversible oneelectron transfer (Fig. 2b-c).

Mixing the oxidized cluster $\mathbf{R e}_{6} \mathbf{o x}$ as potassium salt with $\gamma-C D$ in aqueous solution leads to the formation of single crystals containing the 1:2 host-guest supramolecular arrangements
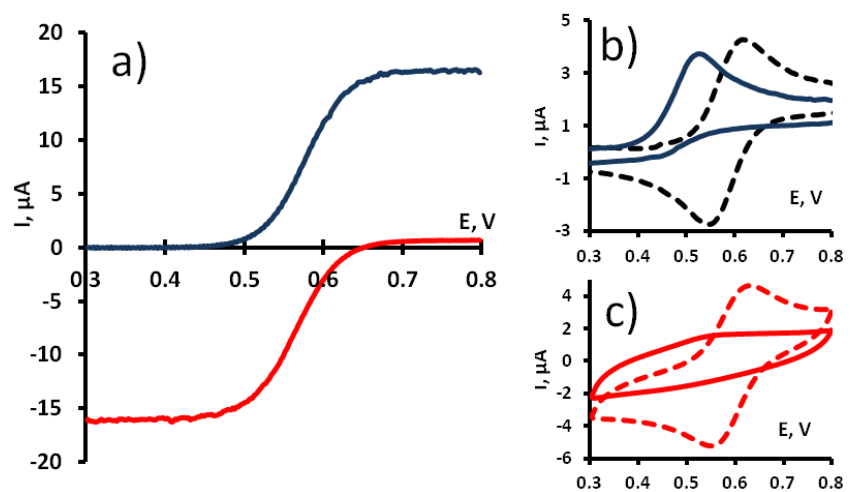

Figure 2. Electrochemical characterizations of oxidized and reduced $\left[\left\{\mathrm{Re}_{6} \mathrm{Se}_{8}\right\}(\mathrm{CN})_{6}\right]^{4-/ 3-}$ clusters. a) Voltamperograms recorded on rotating glassy carbon (GC) electrode of the oxidized (red line) and reduced (blue line) clusters. CVs of the reduced (b) and oxidized (c) clusters in the absence (dotted line) or presence of 3 equivalents of $y-C D$ (solid line). Electrochemical experiments were carried out in $0.5 \mathrm{M} \mathrm{HClO}_{4}$ aqueous solution, using GC and SCE as working and reference electrodes, respectively. noted $\left\{\mathbf{R e}_{6} \mathbf{0 x} @ 2 \mathrm{CD}\right\}^{3-}$. Depending on the introduced ratio $\mathbf{R e}_{6} \mathbf{0 x}: \gamma-C D$, two types of single crystals were isolated and characterized by $\mathrm{X}$-ray diffraction analysis. Crystal type $\mathrm{K}_{3}\left[\left\{\mathbf{R e}_{6} \mathbf{0 x} @ 2 \gamma-\mathrm{CD}\right\} \cdot \gamma-\mathrm{CD}\right] \cdot 33 \mathrm{H}_{2} \mathrm{O}$ (noted $\mathbf{1}$ ) results from solution containing $\mathbf{R e}_{6} \mathbf{O x}$ and $\gamma-C D$ in a 1:3 ratio, respectively while starting from a 1:1 $\mathbf{R e}_{6} \mathbf{0 x}: \gamma-C D$ ratio, $\mathrm{K}_{6}\left[\left\{\mathbf{R e}_{6} \mathbf{0 x} @ 2 \gamma\right.\right.$ $\left.\mathrm{CD}\} \cdot \mathbf{R e}_{6} \mathbf{0 x}\right] \cdot 23 \mathrm{H}_{2} \mathrm{O}$ (abbreviated 2) was isolated. It is worth noting that compound $\mathbf{1}$ is isostructural to the crystal structure obtained previously ${ }^{13}$ using the reduced cluster. Beside, structure of $\mathbf{2}$ corresponds to a new arrangement showing the typical 1:2 adduct $\left\{\mathbf{R e}_{6} \mathbf{0 x} @ 2 \gamma-\mathrm{CD}\right\}^{3-}$ which alternates with a CD-free cluster $\left[\left\{\operatorname{Re}_{6} \mathrm{Se}_{8}\right\}(\mathrm{CN})_{6}\right]^{3-}$. Anyhow, structural features

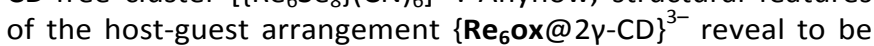
nearly the same to those depicted in $\mathbf{1}$ or $\mathbf{2}$ and do not differ significantly from that built from the reduced cluster species $\left[\left\{\mathrm{Re}_{6} \mathrm{Se}_{8}\right\}(\mathrm{CN})_{6}\right]^{4-}$. Briefly, the octahedral cluster $\left[\left\{\mathrm{Re}_{6} \mathrm{Se}_{8}\right\}(\mathrm{CN})_{6}\right]^{3-}$ appears deeply included within two $\gamma$-CDs facing each other through their secondary faces (Fig. 3a-b). The main significant interactions were identified as hydrogen bonding involving the four equatorial cyano-groups and the hydroxo groups of the secondary rim giving 16 hydrogen bonds with $\mathrm{N} \bullet \bullet O$ distances in the 2.8-3.2 $\AA$ range. Furthermore, analysis of structural data reveals additional weak host-guest interactions such as inward contacts between the selenium atoms and the labelled $\mathrm{H}-3$ hydrogen (see Fig. 4 for numbering) leading to Se $\bullet \bullet H$ separation in the 3.2-3.5 range. Actually, a set of weak and collective attractive interactions arising from hydrogen bonds, ion-dipole and dispersion forces should contribute mainly to the host-guest integrity. Further information about structures $\mathbf{1}$ and 2, including full description of the packing cell are given in ESI.

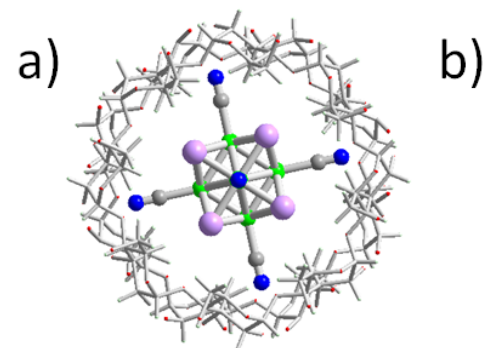

b)

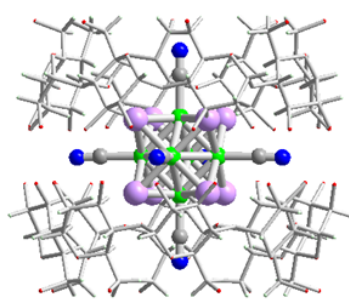

Figure 3. Mixed representations of the solid-state structure of the supramolecular hostguest $\left\{\mathbf{R e}_{6} \mathbf{0 x} @ 2 \gamma-\mathrm{CD}\right\}^{3-} 1: 2$ adduct, depicted from the crystal structures of compounds 1 and 2 , a) along the $C_{4}$ axis (top view), and b) perpendicular to the equatorial plane of the cluster (side view).

Although structures of host-guest arrangement of the reduced and the oxidized derivatives are quite similar in solid state, solution studies showed a highly contrasted behaviour. For instance, ${ }^{1} \mathrm{H}$ NMR titration experiments carried out with $\mathbf{R e}_{6} \mathbf{O} \mathbf{0 x}$ produced new signals, featuring a typical deeply frozen situation on the NMR time scale, while a fast dynamic hostguest exchange regime was evidenced with the use of the reduced species $\mathbf{R e}_{6}$ red (Fig. 4). ${ }^{13}$ Furthermore, a general line broadening was observed in presence of $\mathbf{R e}_{6} \mathbf{0 x}$, concomitantly due to restricted molecular motion in the frozen complex and to Curie relaxation rate arising from the presence of the $\mathbf{R e}_{6} \mathbf{O} \mathbf{x}$ paramagnetic species $(S=1 / 2)$.

Longitudinal $\left(T_{1}\right)$ and transversal $\left(T_{2}\right)$ relaxation measurements were performed with both $\mathbf{R e}_{6} \mathbf{0 x} / \gamma-C D$ and $\mathbf{R e}_{6} \mathbf{r e d} / \gamma-C D$ systems as well as with free $\gamma$-CD for comparison (see ESI for 
further details). The results are summarized in Table 1. Although a slight decrease of the $T_{1}$ and $T_{2}$ relaxation times of $C D$ protons was observed between free-CD and $\mathbf{R e}_{6} \mathbf{r e d} / \gamma-C D$ system, both parameters remain in the same order of
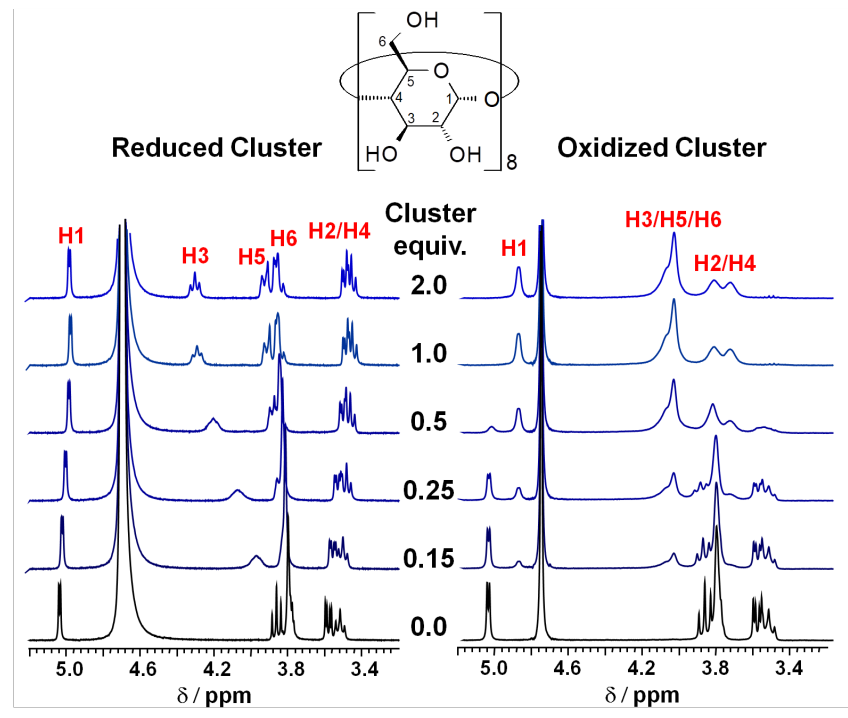

Figure 4. ${ }^{1} \mathrm{H}$ NMR spectra from the titration of $4 \mathrm{mmol} . \mathrm{L}^{-1}$ aqueous solution of $\mathrm{y}-\mathrm{CD}$ by $\left[\left\{\mathrm{Re}_{6} \mathrm{Se}_{8}\right\}(\mathrm{CN})_{6}\right]^{4-}$ cluster (left) and its oxidized form $\left[\left\{\mathrm{Re}_{6} \mathrm{Se}_{8}\right\}(\mathrm{CN})_{6}\right]^{3-}$ (right).

magnitude. However, a drastic decrease of $T_{1}$ is observed in the presence of $\mathbf{R e}_{6} \mathbf{O x}$, especially for the inward $\mathrm{H} 3$ and $\mathrm{H} 5$ protons (Table 1). These protons correspond to those which exhibit the shortest through-space dipolar contacts with the paramagnetic cluster in the host-guest adduct, that thereby increase substantially their relaxation rates. These results highlight the striking contrasted solution behaviour of the host-guest adduct through only one electron transfer within the $\left[\left\{\mathrm{Re}_{6} \mathrm{Se}_{8}\right\}(\mathrm{CN})_{6}\right]^{4-/ 3-}$ species allowing to switch from highly labile host-guest complex to a deeply frozen assembly.

Table 1. $T_{1}$ and $T_{2}$ relaxation times (ms) of $\gamma-C D$ protons in absence and presence of 4 equivalents of cluster $\mathbf{R e}_{6}$ red and $\mathbf{R e}_{6} \mathbf{O x}$.

\begin{tabular}{cccccccc}
\hline & \multirow{2}{*}{ Compound } & $\mathrm{H} 1$ & $\mathrm{H} 2$ & $\mathrm{H} 3$ & $\mathrm{H} 4$ & $\mathrm{H} 5$ & $\mathrm{H} 6$ \\
\hline $\boldsymbol{T}_{\mathbf{1}}{ }^{\mathbf{a}}$ & free CD & 700 & 1120 & 1410 & 650 & 460 & 410 \\
& $\mathbf{R e}_{6}$ red@CD & 640 & 1100 & 1330 & 680 & 540 & 310 \\
& $\mathbf{R e}_{6} \mathbf{0 x @ C D}$ & 300 & 120 & 20 & 210 & 32 & 110 \\
$\boldsymbol{T}_{\mathbf{2}}{ }^{\mathbf{b}}$ & free CD & 291 & 304 & 308 & 299 & 222 & 194 \\
& $\mathbf{R e}_{6}$ red@CD & 255 & 283 & 280 & 248 & 220 & 135 \\
& $\mathbf{R e}_{6}$ ox@CD & 113 & 54 & 42 & 67 & 44 & 57 \\
\hline
\end{tabular}

${ }^{\mathrm{a}}$ The accuracy was ca. $5-10 \%$. ${ }^{\mathrm{b}}$ The accuracy was ca. $2-4 \%$.

Besides, quantitative thermochemical evaluation of the oneelectron transfer during the host-guest process has been provided owing to isothermal calorimetry titration (ITC). ITC data were nicely consistent with a two-step equilibrium model leading to the consecutive formation of the 1:1 and 1:2 hostguest arrangements (see Table 2 and ESI section for further details). ITC analyses related to the inclusion process of $\mathbf{R e}_{6} \mathbf{O x}$ or $\mathbf{R e}_{6}$ red clusters reveals that this contrasted solution behaviour arises mainly from thermodynamic changes and pinpoints an increase of the $K_{1: 1}$ stability constant from 1500 to $220000 \mathrm{M}^{-1}$ through the one-electron transfer process. In less extent, the $\mathrm{K}_{1: 2}$ constant is also altered from increasing value from 300 to about $2000 \mathrm{M}^{-1}$. Furthermore, determination of the thermodynamic contributors to the formation of the $1: 1$ oxidized complex gave a net enthalpy and entropy decrease, significantly more negative than values found for the formation of the homologue reduced-based adduct. ${ }^{13}$

Table 2. Binding constants $K$ involving rhenium octahedral cluster with native $\mathrm{Y}-\mathrm{CD}$ and associated thermodynamic parameters at $\mathrm{T}=298 \mathrm{~K}$.

\begin{tabular}{|c|c|c|c|c|c|}
\hline Compound & Step & $\begin{array}{c}K \\
\left(10^{3} \mathrm{M}^{-1}\right) \\
\end{array}$ & $\begin{array}{c}\Delta_{\mathrm{r}} H^{*} \\
\left(\mathrm{~kJ} \cdot \mathrm{mol}^{-1}\right)\end{array}$ & $\begin{array}{c}T \Delta_{\mathrm{r}} S^{*} \\
\left(\mathrm{~kJ} . \mathrm{mol}^{-1}\right)\end{array}$ & Ref. \\
\hline \multirow[t]{2}{*}{$\mathrm{Re}_{6}$ red } & 1:1 & 1.5 & -30.4 & -12.3 & [13] \\
\hline & $1: 2$ & 0.3 & -56.5 & -42.7 & \\
\hline \multirow[t]{2}{*}{$\mathrm{Re}_{6} \mathrm{OX}$} & 1:1 & 225 & -48.2 & -17.7 & [a] \\
\hline & $1: 2$ & 2 & -20.9 & -1.9 & \\
\hline$\Delta \Delta_{\mathrm{r}} \gamma^{* \mathrm{~b}}$ & 1:1 & & +17.8 & +5.4 & \\
\hline
\end{tabular}

As previously reported in detail by $\mathrm{Nau}$ et al., these thermochemical parameters pinpoint the chaotropic nature of the ionic species involved within the host-guest process. ${ }^{6}$ Such an effect is closely related to the structuring role of hydration shell and then mostly dependent upon the charge density of the ion. Furthermore, this complementary set of data reported in this study demonstrates univocally that the main contributor to the aggregation process arises from structuring changes in the hydration shell around the ions occurring in the aggregation process. As stated above, solid-state packing of the host-guest species in both oxidized and reduced compounds leads to two isostructural arrangements with geometrical parameters that deviate from less than $1 \%$ between the two structures. Furthermore, comparative structural analysis does not allow identifying any significant differences between the two structures, which appear identical within standard deviations (see ESI, table S2). Therefor, structural considerations alone cannot give any comprehensive explanation about the contrasted host-guest behaviour occurring in aqueous solution. Then, the origin of the large host-guest stability must take into account the overall encapsulation process that implies the bulk-water structure recovery arising from the destruction of the hydration shell of the interacting units. Consequently, the main difference between encapsulation processes involving oxidized and reduced ionic clusters should arise from the nature of the hydration shell. Hence, calculations of the variation of enthalpy and entropy $\Delta \Delta_{\mathrm{r}} Y^{*}$ with $Y^{*}=H^{*}$ or TS* according to equation 1 should be useful to give insights about thermochemical changes occurring within the hydration shell through the net decrease of the ionic charge of the cluster from -4 to -3 . In such an assumption, $\Delta \Delta_{r} \gamma^{*}$ could also be approximately expressed by equation 2 where $\left[H^{*}\right]_{\text {hyd,ox }}$ and $\left[H^{*}\right]_{\text {hyd,ed }}$ correspond to the enthalpies of the oxidized and reduced hydrated species, respectively, while $\left[T S^{*}\right]_{\text {hyd,ox }}$ and $\left[T S^{*}\right]_{h y d, \text { red }}$ represent the energetic contribution arising from entropies of the oxidized and reduced hydrated ions.

$$
\begin{aligned}
& \Delta \Delta_{\mathrm{r}} Y^{*}=\left[\Delta_{\mathrm{r}} \mathrm{Y}^{*}\right]_{\mathrm{red}}-\left[\Delta_{\mathrm{r}} \mathrm{Y}^{*}\right]_{\mathrm{ox}} \\
& \Delta \Delta_{\mathrm{r}} Y^{*} \approx\left[\Delta_{\mathrm{r}} Y^{*}\right]_{\mathrm{Hyd}, \mathrm{ox} \rightarrow \mathrm{red}}=\left[\mathrm{Y}^{*}\right]_{\mathrm{hyd}, \mathrm{ox}}-\left[\mathrm{Y}^{*}\right]_{\mathrm{hyd}, \text { red }}
\end{aligned}
$$


As shown in Table 2, calculated value $\Delta \Delta_{\mathrm{r}} H^{*}$ shows that change of the ionic charge from -4 to -3 leads to a significant increase of the enthalpy $\left(\sim 18 \mathrm{~kJ} \cdot \mathrm{mol}^{-1}\right)$, likely due to the weakening of the ion-dipole interactions involving the water molecules at the cluster interface. Furthermore, such an enthalpy increase appears only partially compensated by a slight increase of the entropic contribution $\left(\sim 5 \mathrm{~kJ}^{\mathrm{mol}}{ }^{-1}\right)$, explained by the nearly unchanged octahedral structure which should impose, to some extent, the hydration shell structuring. Then, high enthalpy energy and disordered hydration water molecules correspond both to the fulfilled requirements referring to chaotropic polynuclear species. ${ }^{15,21}$ Thereby, this study shows that the decrease of the charge density within the $\left\{\mathrm{Re}_{6} \mathrm{Se}_{8}(\mathrm{CN})_{6}\right\}$ cluster gives rise to a very large increase of the host-guest stability, identified univocally as a chaotropic effect which become a relevant assembly motif in supramolecular chemistry.

To sum up, we demonstrated in this report that removing one electron from the anionic $\left[\left\{\mathrm{Re}_{6} \mathrm{Se}_{8}\right\}(\mathrm{CN})_{6}\right]^{4-}$ cluster modifies drastically its host-guest stability with $\gamma$-CD, which is directly related to a low charge density and the inherent chaotropic nature of the cluster. Furthermore, the large stability constant $\left(K_{1: 1}=2.25 \cdot 10^{5} \mathrm{M}^{-1}\right)$ observed for the host-guest system involving the oxidized $\left[\left\{\mathrm{Re}_{6} \mathrm{Se}_{8}\right\}(\mathrm{CN})_{6}\right]^{3-}$ cluster and $\gamma-\mathrm{CD}$ corresponds to one of the highest values found among polynuclear clusters and allows to range this species as superchaotrope in the hydration scale classification. ${ }^{15}$ As octahedral clusters represent a class of multifunctional inorganic compounds, featured by intense luminescence, redox, magnetic and chemical properties, tuning their chaotropic nature and then their ionic recognition properties through external redox stimuli should be the way toward the design of responsive and adaptive supramolecular smart materials.

\section{Conflicts of interest}

The authors declare no conflicts of interest.

\section{Acknowledgments}

The Authors gratefully acknowledge financial support from LIA-CNRS CLUSPOM. This work was also supported by public grants overseen by i) University of Versailles Saint Quentin, ii) CNRS, iii) Region Île-de-France, iv) and French National Research Agency (ANR) as part of the "Investissements d'Avenir" program (Labex charmmmat, ANR-11-LBX-0039grant). NIIC thanks the Ministry of Science and Education of the Russian Federation and Russian Science Foundation (No. 15-15-10006). AAl is grateful to Embassy of France in Russian Federation for Vernadsky scholarship for post-graduate students.
1 R. U. Lemieux, Chem. Soc. Rev., 1989, 18, 347-374.

2 C. Cheng, P. R. McGonigal, J. F. Stoddart and R. D. Astumian, ACS Nano, 2015, 9, 8672-8688.

3 Y. Hu, A. Cecconello, A. Idili, F. Ricci and I. Willner, Angew. Chem. Int. Ed., 2017, 56, 15210-15233.

4 M. Faustini, L. Nicole, E. Ruiz-Hitzky and C. Sanchez, Adv. Funct. Mater., 2018, 28, 1704158.

5 F. Hapiot, H. Bricout, S. Menuel, S. Tilloy and E. Monflier, Catal. Sci. Technol., 2014, 4, 1899-1908.

6 K. I. Assaf, M. S. Ural, F. Pan, T. Georgiev, S. Simova, K. Rissanen, D. Gabel and W. M. Nau, Angew. Chem. Int. Ed., 2015, 54, 6852-6856.

7 K. I. Assaf, D. Gabel, W. Zimmermann and W. M. Nau, Org. Biomol. Chem., 2016, 14, 7702-7706.

8 C. Falaise, M. A. Moussawi, S. Floquet, P. A. Abramov, M. N. Sokolov, M. Haouas and E. Cadot, J. Am. Chem. Soc., 2018, 140, 11198-11201.

9 M. A. Moussawi, M. Haouas, S. Floquet, W. E. Shepard, P. A. Abramov, M. N. Sokolov, V. P. Fedin, S. Cordier, A. Ponchel, E. Monflier, J. Marrot and E. Cadot, J. Am. Chem. Soc., 2017, 139, 14376-14379.

10 Y. Wu, R. Shi, Y.-L. Wu, J. M. Holcroft, Z. Liu, M. Frasconi, M. R. Wasielewski, H. Li and J. F. Stoddart, J. Am. Chem. Soc., 2015, 137, 4111-4118.

11 B. Zhang, W. Guan, F. Yin, J. Wang, B. Li and L. Wu, Dalton Trans., 2018, 47, 1388-1392.

12 M. A. Moussawi, N. Leclerc-Laronze, S. Floquet, P. A Abramov, M. N. Sokolov, S. Cordier, A. Ponchel, E. Monflier, H. Bricout, D. Landy, M. Haouas, J. Marrot and E. Cadot, J. Am. Chem. Soc., 2017, 139, 12793-12803.

13 A. A. Ivanov, C. Falaise, P. A. Abramov, M. A. Shestopalov, K. Kirakci, K. Lang, M. A. Moussawi, M. N. Sokolov, N. G. Naumov, S. Floquet, D. Landy, M. Haouas, K. A. Brylev, Y. V. Mironov, Y. Molard, S. Cordier and E. Cadot, Chem. - Eur. J., 2018, 24, 13467-13478.

14 P. A. Abramov, A. A. Ivanov, M. A. Shestopalov, M. A. Moussawi, E. Cadot, S. Floquet, M. Haouas and M. N. Sokolov, J. Clust. Sci., 2018, 29, 9-13.

15 K. I. Assaf and W. M. Nau, Angew. Chem. Int. Ed., 2018, 57, 13968-13981.

16 A. A. Krasilnikova, A. O. Solovieva, A. A. Ivanov, K. E. Trifonova, T. N. Pozmogova, A. R. Tsygankova, A. I. Smolentsev, E. I. Kretov, D. S. Sergeevichev, M. A. Shestopalov, Y. V. Mironov, A. M. Shestopalov, A. F. Poveshchenko and L. V. Shestopalova, Nanomedicine Nanotechnol. Biol. Med., 2017, 13, 755-763.

17 A. A. Ivanov, D. I. Konovalov, T. N. Pozmogova, A. O. Solovieva, A. R. Melnikov, K. A. Brylev, N. V. Kuratieva, V. V. Yanshole, K. Kirakci, K. Lang, S. N. Cheltygmasheva, N. Kitamura, L. V. Shestopalova, Y. V. Mironov and M. A. Shestopalov, Inorg. Chem. Front., 2019, 6, 882-892.

18 A. A. Krasilnikova, M. A. Shestopalov, K. A. Brylev, I. A. Kirilova, O. P. Khripko, K. E. Zubareva, Y. I. Khripko, V. T. Podorognaya, L. V. Shestopalova, V. E. Fedorov and Y. V. Mironov, J. Inorg. Biochem., 2015, 144, 13-17.

19 P. Kumar, H. P. Mungse, S. Cordier, R. Boukherroub, O. P. Khatri and S. L. Jain, Carbon, 2015, 94, 91-100.

20 J. C. P. Gabriel, K. Boubekeur, S. Uriel, and P. Batail, Chem. Rev., 2001, 101, 2037-2066.

21 T. Buchecker, P. Schmid, S. Renaudineau, O. Diat, A. Proust, A. Pfitzner and P. Bauduin, Chem. Commun., 2018, 54, 18331836.

\section{Notes and references}

